\title{
BMJ Open Prevalence of childhood hearing impairment of different severities in urban and rural areas: a nationwide population-based study in Taiwan
}

\author{
Cheng-Yu Lin, ${ }^{1,2}$ Yen-Cheng Tseng, ${ }^{3}$ How-Ran Guo, ${ }^{2,4}$ Der-Chung Lai ${ }^{5,6}$
}

To cite: Lin C-Y, Tseng Y-C, Guo H-R, et al. Prevalence of childhood hearing impairment of different severities in urban and rural areas: a nationwide population-based study in Taiwan. BMJ Open 2018;8:e020955. doi:10.1136/ bmjopen-2017-020955

- Prepublication history for this paper is available online. To view these files please visit the journal online (http://dx.doi. org/10.1136/bmjopen-2017020955).

H-RG and D-CL contributed equally.

Received 3 December 2017 Revised 27 February 2018 Accepted 7 March 2018
Check for updates

For numbered affiliations see end of article.

Correspondence to Professor How-Ran Guo; hrguo@mail.ncku.edu.tw

\section{ABSTRACT}

Objective Childhood hearing impairment (CHI) is a major developmental disability, but data at the national level are limited, especially those on different severities. We conducted a study to fill this data gap.

Design A nationwide study on the basis of a reporting system.

Setting To provide services to disabled citizens, the Taiwanese government maintains a registry of certified cases. Using data from this registry, we estimated prevalence rates of $\mathrm{CHI}$ of different severities from 2004 to 2010 and made comparisons between urban and rural areas.

Participants Taiwanese citizens $\leq 17$ years old. Primary outcome measures To qualify for $\mathrm{CHI}$ disability benefits, a child must have an unaided pure-tone better ear hearing level at $0.5,1$ and $2 \mathrm{kHz}$ with an average $\geq 55$ decibels $(\mathrm{dB})$, confirmed by an otolaryngologist. The severity was classified by pure-tone better ear hearing level as mild (55-69 dB), moderate $(70-89 \mathrm{~dB})$ and severe ( $\geq 90 \mathrm{~dB}$ ).

Results The registered cases under 17 years old decreased annually from 4075 in 2004 to 3533 in 2010 , but changes in the prevalence rate were small, ranging from 7.62/10 000 in 2004 to 7.91/10 000 in 2006. The prevalence rates of mild $\mathrm{CHI}$ increased in all areas over time, but not those of moderate or severe $\mathrm{CHI}$. Rural areas had higher overall prevalence rates than urban areas in all years, with rate ratios (RRs) between 1.01 and 1.09. By severity, rural areas had higher prevalence rates of mild (RRs between 1.08 and 1.25) and moderate (RRs between 1.06 and 1.21) $\mathrm{CHI}$ but had lower prevalence rates of severe $\mathrm{CHI}$ (RRs between 0.92 and 0.99 ).

Conclusion While rural areas had higher overall prevalence rates of $\mathrm{CH}$ than urban areas, the RRs decreased with $\mathrm{CH}$ severity. Further studies that identify factors affecting the rural-urban difference might help the prevention of $\mathrm{CHI}$.

\section{INTRODUCTION}

Hearing impairment (HI) is a global problem, and the WHO estimated that 360 million people (including 32 million children) have disabling HI. ${ }^{1}$ Most patients live in low-income and middle-income countries, and $25 \%$ are

\section{Strengths and limitations of this study}

- Data on the same population were collected over a 7 -year period, which allows the assessment of time trends.

- The study number of cases was large, over 3533 cases in 2010 alone.

- We have information on severity, which is rarely reported by large-scale studies.

- This study used administrative data, which do not cover cases who are not detected or who have never received services from the administration.

- Data on individual cases were not provided by the registry, which hindered more detailed analyses.

born with or acquire HI during childhood. Compared with infants born in resourcerich countries, infants born in resource-poor countries have a nearly twofold risk. ${ }^{2-4}$ The costs of the education support to children with better ear hearing level (BEHL) $>50 \mathrm{~dB}$ was estimated as $\$ 3.9$ billion. ${ }^{5}$ Compared with normal children, patients with childhood HI (CHI) have difficulties in language development, speech production and cognition, which in turn affect their academic performance, vocational attainment and socioemotional competence. ${ }^{267}$

The World Health Assembly affirmed the importance of interventions in control preventable $\mathrm{HI}^{8}$ and recommended population-based epidemiological studies to determine the prevalence rate and causes of $\mathrm{HI}$ in all nations for targeting of preventive efforts. ${ }^{2}$ The reported prevalence rates of CHI varied widely around the world. ${ }^{9-13}$ Most studies focus on either rural or urban populations, even though comparing the difference between the two is important. The urban-rural differences might be attributable to differences in cultural perceptions regarding the impact of HI, diagnosis and treatment, ${ }^{14}$ but efforts are needed to investigate the differences further. 
In 1980, the Taiwanese government constructed a system to certify disabled residents and to provide them with various services. The central government keeps a registry of certified cases, ${ }^{15}$ presenting a rare opportunity for studying $\mathrm{CHI}$ at the national level. The objectives of this study were to estimate the prevalence rates of CHI of different severities and to evaluate the differences between urban and rural areas.

\section{METHODS}

\section{The disability registry system in Taiwan}

In Taiwan, the Disabled Welfare Act was promulgated in $1980 .{ }^{16}$ Accordingly, the local governments began to certify seven types of patients with disabilities, including 'hearing impairment or balance disability.' When the Act was revised to become the People with Disabilities Rights Protection Act in $1997,{ }^{17}$ the 'hearing impairment or balance disability' category was divided into two: $\mathrm{HI}$ and 'balance disability.'

Individuals can make applications for certification through their local government in the residential area. ${ }^{18-20}$ These local governments report certified cases to the central government. The registry of cases was first maintained by the Ministry of the Interior and then by the Ministry of Health and Welfare after the reorganisation of the government in $2013 .{ }^{19}$ Because the registry identifies cases by the unique National Identification Numbers, each case is identified as one entity only.

\section{Case definition of $\mathrm{CHI}$}

When a child is suspected of having HI, parents or guardians can apply for certification. To qualify for disability benefits, a child must have an unaided pure-tone BEHL at $0.5,1$ and $2 \mathrm{kHz}$ (pure-tone average [PTA]) with an average $\geq 55$ decibels $(\mathrm{dB})$ and confirmation by an otolaryngologist accredited by the government. ${ }^{18}{ }^{19}$ Different hearing tests are used to check for hearing disability in children less than 5 years of age. Neonatal HI is identified by the otoacoustic emissions screening with referral for diagnostic auditory brainstem response assessment. Visual reinforcement audiometry and play audiometry are used to test $\mathrm{HI}$ in older babies and young children. In cases with suspected malingering or difficulties in testing, an auditory brainstem response is applied.

According to the Taiwanese government, ${ }^{19}$ the severity of $\mathrm{HI}$ is defined as 'mild' with PTA $\geq 55 \mathrm{~dB}$ BEHL and $<70$ dB BEHL, 'moderate' with PTA $\geq 70 \mathrm{~dB}$ BEHL and $<90$ $\mathrm{dB}$ BEHL and 'severe' with PTA $\geq 90 \mathrm{~dB}$ BEHL. In order to continue to receive the disability benefits, a registered case needs to be re-evaluated every 3 years by an otolaryngologist accredited by the government.

\section{Data collection}

Using the nationwide registry data of HI, we conducted a study that included all children ( $\leq 17$ years old) with Taiwanese citizenship. Each year, the government publishes a Statistical Yearbook. ${ }^{15}$ We obtained the data from the central government, but they are available since 2004 only. Furthermore, with the reorganisation of administrative regions in 2011, one of the rural regions was merged into an urban region. While the impact of the reorganisation on the classification was small, it made the population subdivisions incomparable before and after the reorganisation. Therefore, we only analysed the data until 2010. To calculate the prevalence rates, we obtained the total number of individuals in each age group from the Monthly Bulletin of Interior Statistics. ${ }^{21}$ The numbers were used as the denominators in estimating prevalence rates because the case ascertainment of the registry is through reporting by caregivers, and all eligible children are under continuous watch of the caregivers and will be reported when they become cases.

According to the Directorate-General of Budget, Accounting and Statistics, we defined an 'urban area' as a city or county with $>50 \%$ of the population living in metropolitan regions. ${ }^{22}$ In Taiwan, there are 7 cities and 18 counties, of which 7 cities and 5 counties were categorised as urban areas, and the remaining 13 counties were categorised as rural areas.

\section{Statistical analysis}

We estimated the prevalence rate of $\mathrm{CHI}$ in a rural or urban area by dividing the number of cases by the number of individuals each year and evaluated the trend over time. According to the yearbooks, ${ }^{15}$ we categorised the age into five groups ( $<3$ years, $3-5$ years, $6-11$ years, 12-14 years, and $15-17$ years). We calculated the overall prevalence rates, as well as the prevalence rates by severity, and evaluated the trends over time.

To evaluate the differences between urban and rural areas, we estimated the prevalence rate ratio (RR) by dividing the prevalence rate of rural areas by that of urban areas. A 95\% CI was calculated for each RR to evaluate its statistical significance.

We used the $\chi^{2}$ test for trend to evaluate trends of changes in the prevalence rates over time and across age groups. To evaluate trends of changes in prevalence RRs over time and across age groups, we used linear regressions. In addition, we used analysis of variance for repeated measures to evaluate trends of changes in the prevalence RRs among three different severity groups.

We conducted the analyses using SAS V.9.1 and performed all statistical tests at the significance level of 0.05 .

\section{Patient and public involvement}

This study was based on secondary data analysis, and there was no patient or public involvement.

\section{RESULTS}

The trend of the overall prevalence rate by area

From 2004 to 2010, the registered cases under 17 years old decreased from 4075 to 3533 , with a decreasing time trend. However, the changes in prevalence rates were 
small, ranging from 7.62/10 000 in 2004 to $7.91 / 10$ 000 in 2006, without a remarkable time trend, mainly because of the decreasing number of newborns each year. The prevalence rates in rural areas fluctuated between $7.70 / 10000$ and 8.18/10 000, without remarkable time trends (table 1). The prevalence rates in urban areas also fluctuated, between 7.50/10 000 and 7.85/10 000, without remarkable time trends (table 2). Rural areas had higher overall prevalence rates in all years, and the rural-to-urban prevalence RRs ranged from 1.01 to 1.09 (with $\mathrm{P}<0.05$ in 2008 and 2009), without remarkable time trends (table 3 ).

\section{The trends of prevalence rates by age}

In rural areas, the prevalence rates in age groups $<3$ years, $3-5$ years, $6-11$ years, $12-14$ years, and $15-17$ years was $2.31-4.90 / 10000,5.91-7.75 / 10000,7.61-8.39 / 10$ $000,8.97-9.73 / 10000$, and $9.71-12.00 / 10000$, respectively (table 1 ). In each year, prevalence rates increased with age $\left(\mathrm{P}<0.01\right.$ for all $\chi^{2}$ tests for trend). Over time, the prevalence rates increased in age groups $<3$ years $(\mathrm{P}<0.01$, increased by $71.0 \%$ from 2004 to 2010$)$ and $3-5$ years $(\mathrm{P}<0.05$, increased by $23.6 \%)$ but decreased in the age group $15-17$ years $(\mathrm{P}<0.01$, decreased by $19.1 \%)$.

In urban areas, the prevalence rates in age groups $<3$ years, $3-5$ years, $6-11$ years, $12-14$ years and $15-17$ years was $2.24-4.01 / 10000,5.90-6.82 / 10000,7.37-7.84 / 10$ $000,8.18-9.25 / 10000$ and $9.21-11.17 / 10000$, respectively (table 2 ). In each year, prevalence rates increased with age $(\mathrm{P}<0.01$ in all years $)$. The prevalence rates increased in the age group $<3$ years over time $(\mathrm{P}<0.01$, increased by $79.0 \%$ ) but decreased in age groups $12-14$ years and $15-17$ years $(\mathrm{P}<0.05$ for both, decreased by $8.3 \%$ and $17.6 \%$, respectively).

\section{The trends of prevalence rates by severity and area}

For mild CHI, the overall prevalence rates increased over time in both rural and urban areas $(\mathrm{P}<0.05$ for both) (table 4). For moderate CHI, overall prevalence rates decreased over time in urban areas $(\mathrm{P}<0.01)$, but no remarkable trends were observed in rural areas. For severe CHI, the changes in overall prevalence rates were small in both rural and urban areas and without any remarkable time trends.

Rural areas had higher overall prevalence rates of mild CHI in all years, and the differences reached statistical significance in all years except 2005 and 2007. Rural areas also had higher prevalence rates of moderate $\mathrm{CHI}$ in all years, but the difference reached statistical significance in 2008 only. For severe CHI, prevalence rates in urban areas were slightly higher in all years, but none of the differences reached statistical significance (table 4). The changes in rural-to-urban RR were small in all severity groups and without any remarkable time trends. Nevertheless, the mean of rural-to-urban RR in mild, moderate and severe CHI was $1.15,1.10$ and 0.96 , respectively, indicating a decreasing trend $(\mathrm{P}<0.01)$. The rural-to-urban

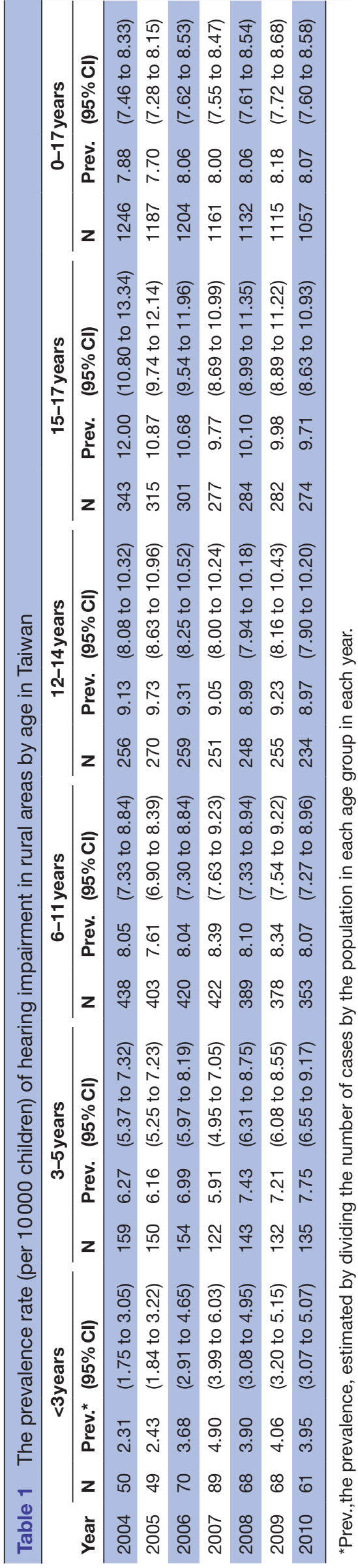



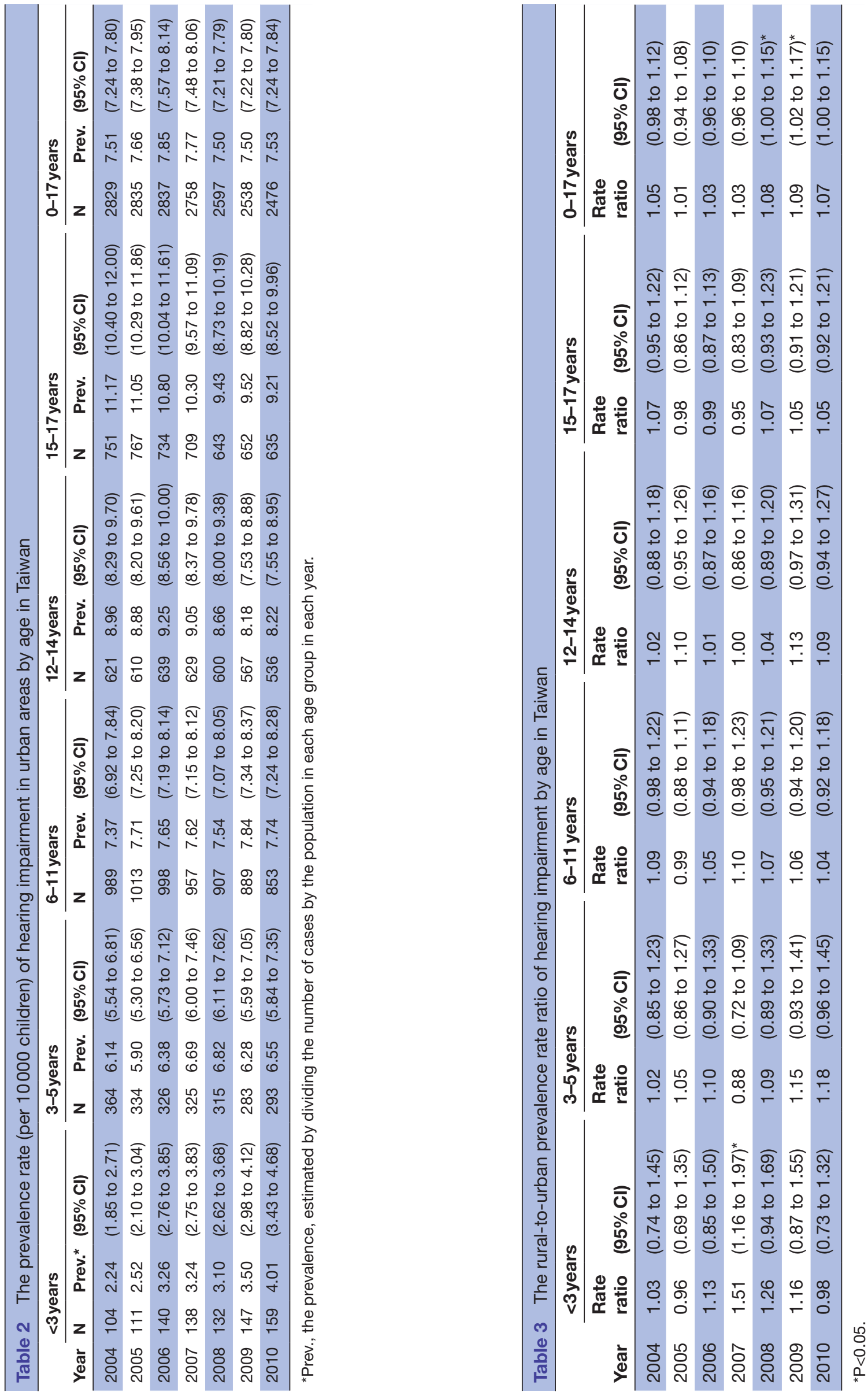
Table 4 The overall rural-to-urban prevalence rate ratio of hearing impairment by severity in Taiwan

\begin{tabular}{|c|c|c|c|c|c|c|c|c|c|c|c|c|}
\hline \multirow[b]{3}{*}{ Year } & \multicolumn{4}{|l|}{ Mild } & \multicolumn{4}{|c|}{ Moderate } & \multicolumn{4}{|c|}{ Severe } \\
\hline & \multicolumn{2}{|l|}{ Prev.† } & \multirow{2}{*}{$\begin{array}{l}\text { Rate } \\
\text { ratio }\end{array}$} & \multirow[b]{2}{*}{ (95\% Cl) } & \multicolumn{2}{|l|}{ Prev. } & \multirow{2}{*}{$\begin{array}{l}\text { Rate } \\
\text { ratio }\end{array}$} & \multirow[b]{2}{*}{ (95\% Cl) } & \multicolumn{2}{|l|}{ Prev. } & \multirow{2}{*}{$\begin{array}{l}\text { Rate } \\
\text { ratio }\end{array}$} & \multirow[b]{2}{*}{$(95 \% \mathrm{Cl})$} \\
\hline & Rural & Urban & & & Rural & Urban & & & Rural & Urban & & \\
\hline 2005 & 2.49 & 2.28 & 1.09 & (0.97 to 1.23 ) & 1.95 & 1.85 & 1.06 & (0.92 to 1.21 ) & 3.26 & 3.53 & 0.92 & (0.83 to 1.02$)$ \\
\hline 2006 & 2.69 & 2.38 & 1.13 & $(1.00 \text { to } 1.27)^{\star}$ & 1.97 & 1.84 & 1.07 & (0.93 to 1.23 ) & 3.41 & 3.62 & 0.94 & (0.85 to 1.04$)$ \\
\hline 2008 & 2.64 & 2.32 & 1.14 & $(1.01 \text { to } 1.29)^{\star}$ & 2.12 & 1.76 & 1.21 & $(1.05 \text { to } 1.39)^{\star}$ & 3.30 & 3.42 & 0.96 & (0.87 to 1.07 ) \\
\hline 2009 & 2.93 & 2.35 & 1.25 & $(1.10 \text { to } 1.40)^{\star}$ & 1.98 & 1.74 & 1.14 & (0.99 to 1.31$)$ & 3.27 & 3.41 & 0.96 & (0.86 to 1.07 ) \\
\hline 2010 & 2.95 & 2.45 & 1.21 & $(1.07 \text { to } 1.36)^{\star}$ & 1.76 & 1.64 & 1.07 & (0.92 to 1.25$)$ & 3.37 & 3.45 & 0.98 & (0.87 to 1.09 ) \\
\hline
\end{tabular}

${ }^{*} \mathrm{P}<0.05$

†Prev., the prevalence per 10000 children, estimated by dividing the number of cases by the population in each age group in each year.

RR decreased with severity in all years except for 2007 and 2008.

\section{DISCUSSION}

Prevalence data on CHI between urban and rural areas from large-scale studies are limited, and the reported prevalence rates range widely. We conducted a search of literature in the PubMed database and identified 16 studies on the prevalence rate of low-frequency CHI, which defined $\mathrm{HI}$ by $\mathrm{dB}$ hearing level (HL) values and included rural and/or urban participants, and 11 of them used cutoffs $\geq 30 \mathrm{~dB}$ (table 5). ${ }^{29-11} 132023-32$ The variation in reported prevalence rates may mainly be attributable to differences in case definition, age range, and case-finding methods. ${ }^{33}$ Factors such as genetic makeup, healthcare accessibility, and socioeconomic status may also have contributions. ${ }^{11-13}$ The differences make comparisons among studies difficult. For example, the case definition of severe $\mathrm{CHI}$ in our study was $\geq 90 \mathrm{~dB}$ BEHL, and the 3.4/10 000 prevalence rate in the rural areas in 2010 was lower than those reported by a study in Saudi Arabia (3.9/10 000) ${ }^{9}$ and a study in India (35.2/10 $000)^{10}$ adopting similar criteria. However, the age ranges used were different, making the comparison difficult. The above limitations highlight the need for standardisation to enhance the quality and comparability of study results. For example, the WHO recommends disabling $\mathrm{HI}$ in children be defined as a permanent unaided BEHL $>30 \mathrm{~dB}$ taken as the average BEHL for frequencies $0.5,1$, 2 and $4 \mathrm{kHz}$; while we were unable to adopt the standards because the lack of data on individual cases, of the 11 previous studies identified from the systematic literature review, none adopted the WHO standards, even though most of them had data on individual cases. Standardisation can allow direct future comparisons of studies as well as establishing normative baseline data to illuminate potential intervention strategies. ${ }^{12}$

Our major finding of a higher prevalence rate of CHI in rural areas was consistent with the results of previous studies in other countries. ${ }^{202}$ In 2009 , the rural-to-urban prevalence RR was 0.96 (not statistically significant) in severe cases and 1.14 (not statistically significant) in moderate cases, but it was 1.25 (statistically significant) in mild cases, making the overall RR (1.09) statistically significant. In a study in Tanzania, in which 802 primary school children were examined using pure tone audiometry and $\mathrm{HI}$ was defined as a low-frequency PTA threshold of $>5 \mathrm{~dB}$ HL in the frequencies of $0.5,1$ and $2 \mathrm{kHz},{ }^{24}$ the prevalence rate of CHI was 1102.4/10 000 among rural children, while it was only 755.6/10 000 among urban children $(\mathrm{P}<0.05)$. Similarly, in a survey in Nepal, school children with a diagnosis of otitis media with effusion (aged from 4-13 years) underwent audiometric assessment, and the prevalence rate of $\mathrm{HI}$, defined as a middle-frequency PTA threshold of $>25 \mathrm{~dB}$ HL in the frequencies of $0.5,1$, 2 and $4 \mathrm{kHz}$, was higher among rural children $(2700.0 / 10$ 000 vs $400.0 / 10000, \mathrm{P}<0.05) .^{20}$

Some studies comparing CHI between urban and rural areas reported findings that are different from our observations. A study in China examined 6626 residents with an age range from 1 month to 90 years using the WHO definitions of $\mathrm{HI}$ and found no differences between urban and rural areas $(19.7 \%$ vs $15.7 \%$ reduction in $\mathrm{dB}$ HL, P>0.05) ${ }^{34}$ However, the report did not have separate data on CHI specifically, and therefore it is difficult to draw a conclusion on the difference in CHI. A study in Tanzania examined 854 school children from one urban district and one rural district by screening audiometry (air conduction) and found that the prevalence of bilateral HI was higher in the urban district $(10.5 \%$ vs $4.7 \%){ }^{35}$ However, they did not include sensory HI, and therefore it is difficult to compare their data with our findings directly.

Some studies have investigated the possible aetiological factors of the high prevalence rate of $\mathrm{CHI}$ in rural populations. A study on 335 school children between 6 and 19 years of age in an impoverished area of Peru identified the following risk factors for CHI: neonatal jaundice, seizure, hospitalisation, recurrent otitis media, past otorrhea, family history of $\mathrm{HI}$ at $<35$ years, tympanic membrane 
Table 5 The prevalence rate (per 10000 children) of low-frequency hearing impairment ( $\geq 30 \mathrm{~dB}$ hearing level $[\mathrm{HL}]$ in the better ear) defined by $\mathrm{dB}$ values in different studies

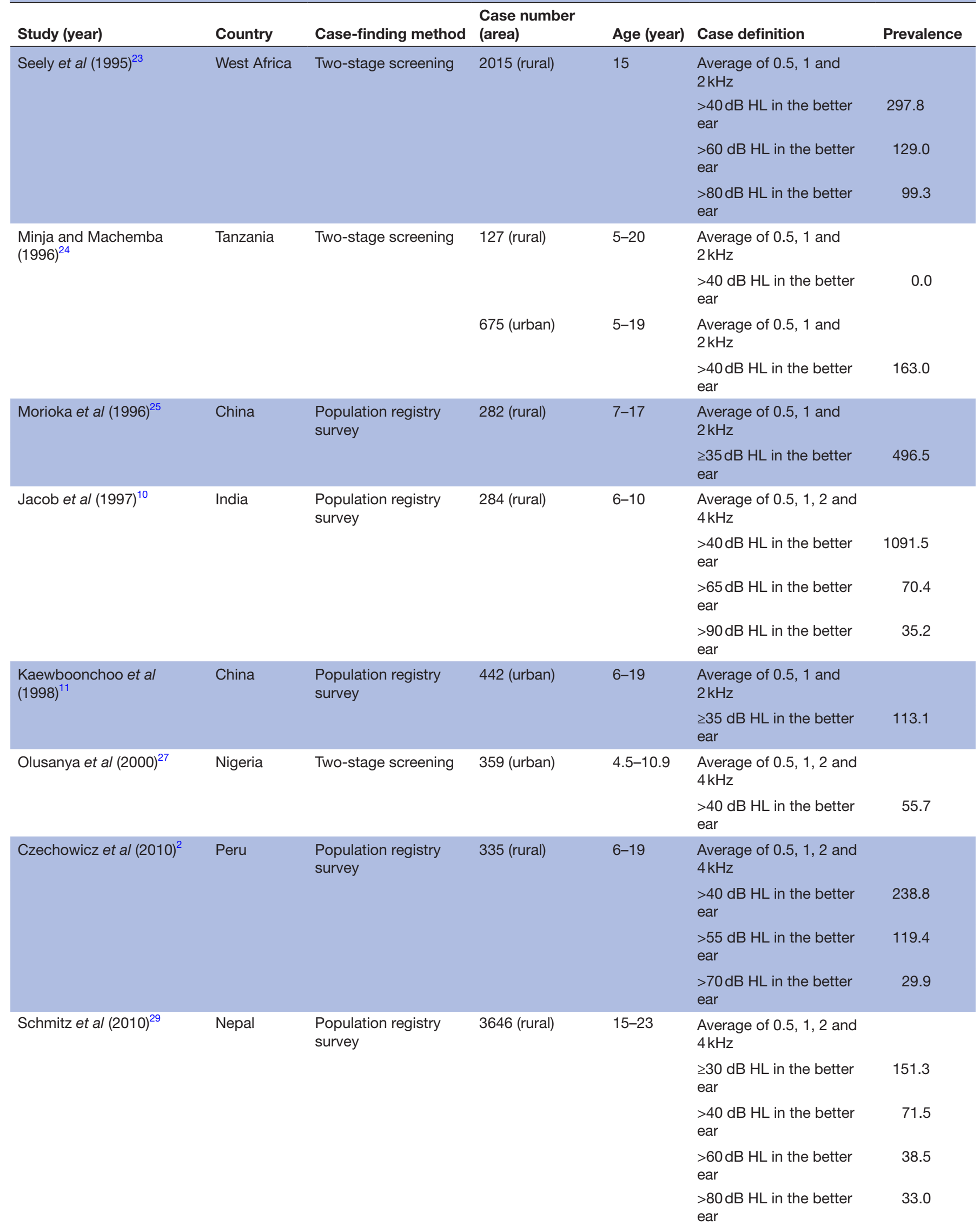




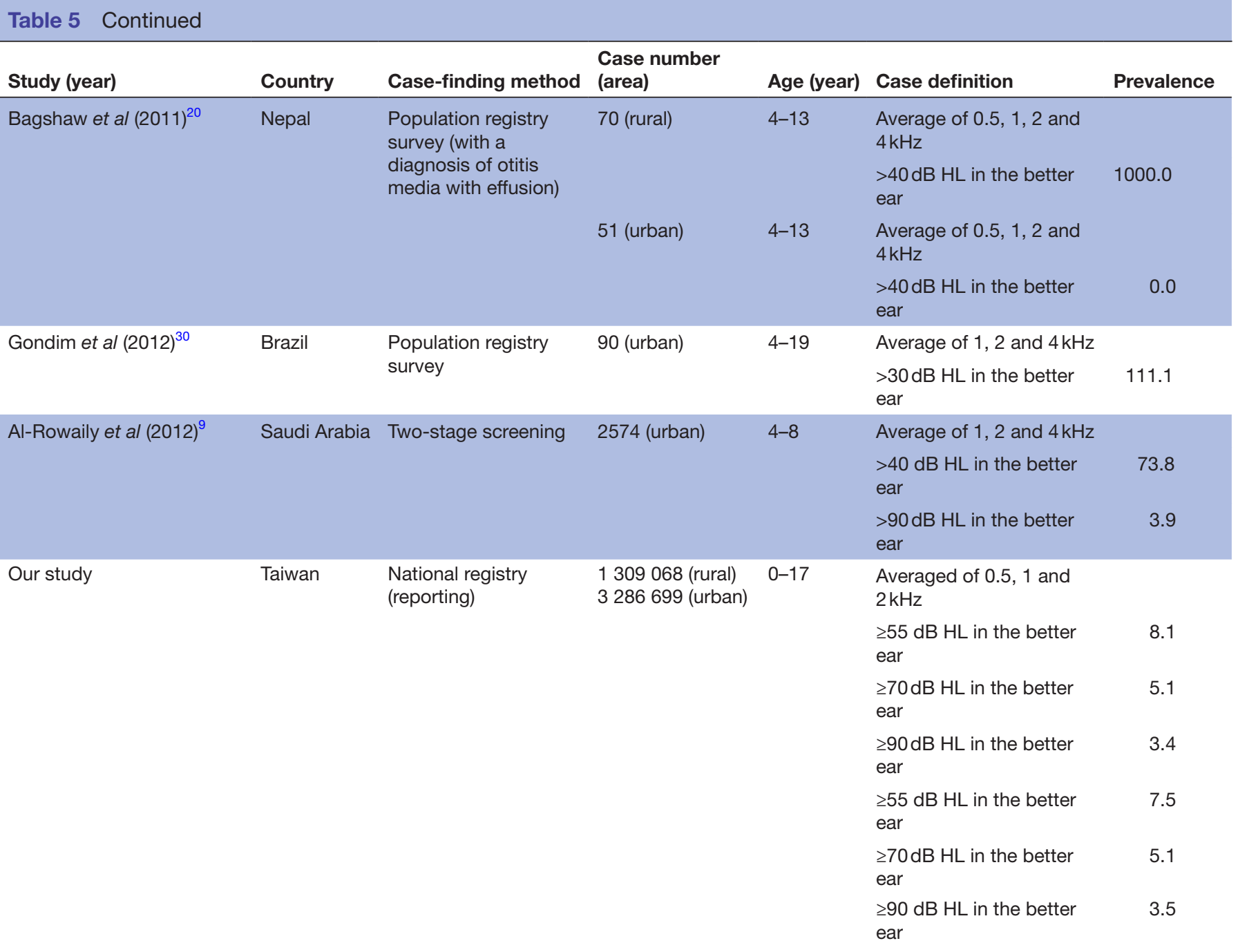

abnormality, cerumen impaction, and eustachian tube dysfunction. ${ }^{2}$ This study proposed that untreated middle ear disease in the context of limited access to paediatric care may be a major risk factor for rural CHI. In a rural primary school in south India, hearing assessments were performed on 284 students (from 6 to 10 years old), and middle ear disease was found to be the predominant cause of CHI. ${ }^{10}$ An investigation of $\mathrm{HI}$ in 75 Yemeni children (0.6-15 years) with chronic suppurative otitis media found that middle ear disease predominantly caused an $\mathrm{HI}$ of 26-60 dB HL. ${ }^{36}$ According to these findings, middle ear disease appears to be major cause of CHI in rural areas, mainly leading to $\mathrm{HI}$ in the range of 26-60 dB HL. In our study, we found that mild CHI (55-69 dB BEHL) was more prevalent in the rural areas in all years, with most of the rural-to-urban RRs reaching statistical significance, while the prevalence rates of $\mathrm{CHI}$ in the other two higher severity categories ( $\geq 70 \mathrm{~dB} \mathrm{HL}$ ) were similar between rural and urban areas. Therefore, we speculate that a higher prevalence of untreated middle ear disease in rural areas contributed, at least in part, to the ruralurban differences observed in our study.
In each year, the prevalence rates of CHI in both rural and urban areas increased with age. This finding was also noted in the Metropolitan Atlanta Developmental Disabilities Surveillance Program in the USA, ${ }^{37}$ which found that the prevalence rate of $\mathrm{CHI}>40 \mathrm{~dB}$ HL increased steadily from 6.7/10 000 among 3-year-old children to 13.8/10 000 for 10-year-old children. Likewise, a study in the UK found that the prevalence rate of CHI $>40 \mathrm{~dB}$ HL rose from 9.1/10 000 among 3-year-old children to $16.5 / 10000$ among children 9-16 years old. ${ }^{38}$ Because HI was rarely fatal and a substantial proportion of serious cases were not curable, ${ }^{33}$ it is reasonable that age appears to be a main determinant of the prevalence rate of CHI. In addition, both newly acquired $\mathrm{HI}$ and the progress of impairment severity might also contribute to the increasing trend in the prevalence of $\mathrm{CHI}$ associated with age.

We found that the prevalence rates of $\mathrm{CHI}$ in the age group $<3$ years significantly increased over time. In urban areas, the rates increased significantly by $79 \%$ from 2004 to 2010 , and they increased significantly by $71 \%$ in rural areas. We speculated that one of the main causes of this 
was the implementation of the newborn hearing screening (NHS) programme in Taiwan. As early diagnosis and early intervention of congenital HI have been demonstrated effective in reducing its negative impacts on a child's development, the Health Promotion Administration of Taiwan began the promotion of NHS using otoacoustic emission and automated auditory brainstem response in $2003 .{ }^{39}$ We believe that through increasing the awareness of parents and professionals and promoting easier access to NHS, the registration of CHI cases has increased. According to Taiwan's official reports, the participation rate of NHS has increased from $4.0 \%$ in 2002 to $71.1 \%$ in 2010 , and $97.8 \%$ of the baby-delivering institutions offered NHS services in $2013^{40}$. Another possible cause is that Taiwan Health Promotion Administration has also implemented the Hearing Screening Plan for Pre-School Age Children in communities and kindergartens. In 2013, for example, 138197 children were thus screened, yielding a screening rate of $81.6 \%$, much higher than the $30.3 \%$ rate in $2002 .{ }^{40}$

In contrast with previous studies, our study has some unique features. While most previous studies were cross-sectional surveys, we have data on the same population over time. In most previous large-scale studies, data collection was just a one-time effort, but our study included 7years' worth of data, which allows for the assessment of time trends. In addition, our study has a very large number of cases, over 3533 cases in 2010 alone, and therefore we can generate reliable statistical estimates. We also have specific information on severity, which is rarely reported by large-scale studies.

However, our study also has some limitations. We used 'administrative prevalence' data, which did not cover cases that were not detected or never received services from the administration. Also, data on individual cases provided by the registry were limited, which hindered the study of the aetiology of the differences between rural and urban areas. Investigations to clarify the aetiology of the difference should be performed, which would help prevention and health education to reduce the risk of CHI. Furthermore, we used city/county as the unit for observation, but there may be both urban and rural townships within a county. Therefore, using township as the unit of study may lead to more precise classification. Unfortunately, such data were unavailable from the Taiwan government. Nonetheless, this limitation tends to underestimate the difference in CHI prevalence between rural and urban areas, instead of overestimating it, and since we observed a statistically significant difference, its effect is unlikely to change our conclusions.

In conclusion, we found that the prevalence of $\mathrm{CHI}$ had remained similar from 2004 to 2010 in Taiwan. During this period, rural areas generally had higher prevalence rates than urban areas. This difference was attributable to the higher prevalence rates of mild CHI (55-69 dB BEHL). The rural-to-urban prevalence RRs generally decreased with severity. In addition, we found that the prevalence rate in the age group $<3$ years had increased remarkably in both rural and urban areas, which might be attributable to the implementation of the NHS programme. We hope these findings can cast some light on the prevention and control of CHI.

\section{Author affiliations}

${ }^{1}$ Department of Otolaryngology, National Cheng Kung University Hospital, College of Medicine, National Cheng Kung University, Tainan, Taiwan

${ }^{2}$ Department of Environmental and Occupational Medicine, National Cheng Kung University Hospital, College of Medicine, National Cheng Kung University, Tainan,

Taiwan

${ }^{3}$ Language Education Center, Department of Tourism, Food, and Beverage

Management, Chang Jung Christian University, Tainan, Taiwan

${ }^{4}$ Department of Environmental and Occupational Health, College of Medicine, National Cheng Kung University, Tainan, Taiwan

${ }^{5}$ Department of Physical Medicine and Rehabilitation, Ditmanson Medical Foundation Chia-Yi Christian Hospital, Chia-Yi City, Taiwan

${ }^{6}$ Department of Senior Citizen Service Management, Chia Nan University of Pharmacy and Science, Tainan, Taiwan

Acknowledgements We would like to thank the Department of Statistics of Ministry of Health and Welfare and the Department of Statistics of Ministry of the Interior for providing the registry data. Furthermore, we would also thank $\mathrm{Mr}$ Cheng-Hsin Yeh for his assistance in statistical analysis.

Contributors All authors participated in the design or implementation of the study or the analysis and interpretation of findings. All authors were involved in all phases of the study. D-CL and H-RG contributed to the study design. H-RG was the principal investigator. D-CL, C-YL and H-RG contributed to the implementation of the study, statistical analysis and interpretation of the efficacy results. All authors had access to the study data and contributed to data interpretation. The report was drafted by $\mathrm{C}-\mathrm{YL}$, and all authors reviewed and revised drafts of the manuscript and approved the final version.

Funding This study was funded by the Ditmanson Medical Foundation Chia-Yi Christian Hospital Research Program through Grant No. R105-006.

Competing interests None declared.

Patient consent Detail has been removed from this case description/these case descriptions to ensure anonymity. The editors and reviewers have seen the detailed information available and are satisfied that the information backs up the case the authors are making.

Ethics approval The Institution Review Board of the Ditmanson Medical Foundation Chia-Yi Christian Hospital.

Provenance and peer review Not commissioned; externally peer reviewed. Data sharing statement № additional data available.

Open Access This is an Open Access article distributed in accordance with the Creative Commons Attribution Non Commercial (CC BY-NC 4.0) license, which permits others to distribute, remix, adapt, build upon this work non-commercially, and license their derivative works on different terms, provided the original work is properly cited and the use is non-commercial. See: http://creativecommons.org/ licenses/by-nc/4.0/

(c) Article author(s) (or their employer(s) unless otherwise stated in the text of the article) 2018. All rights reserved. No commercial use is permitted unless otherwise expressly granted.

\section{REFERENCES}

1. World Health Organization. Deafness and hearing loss (Fact Sheet No. 312). 2015

2. Czechowicz JA, Messner AH, Alarcon-Matutti E, et al. Hearing impairment and poverty: the epidemiology of ear disease in Peruvian schoolchildren. Otolaryngol Head Neck Surg 2010;142:272-7.

3. Olusanya BO, Ruben RJ, Parving A. Reducing the burden of communication disorders in the developing world: an opportunity for the millennium development project. JAMA 2006;296:441-4.

4. Smith RJ, Bale JF, White KR. Sensorineural hearing loss in children. Lancet 2005;365:879-90. 
5. World Health Organization. Global costs of unaddressed hearing loss and cost-effectiveness of interventions: a WHO report. 2017.

6. Hintermair M. Parental resources, parental stress, and socioemotional development of deaf and hard of hearing children. $J$ Deaf Stud Deaf Educ 2006;11:493-513.

7. Niskar AS, Kieszak SM, Holmes A, et al. Prevalence of hearing loss among children 6 to 19 years of age: the third national health and nutrition examination survey. JAMA 1998;279:1071-5.

8. World Health Organization. WHA48.9 Prevention of hearing impairment. 1995

9. Al-Rowaily MA, AlFayez Al, AlJomiey MS, et al. Hearing impairments among Saudi preschool children. Int J Pediatr Otorhinolaryngol 2012;76:1674-7.

10. Jacob A, Rupa V, Job A, et al. Hearing impairment and otitis media in a rural primary school in south India. Int $J$ Pediatr Otorhinolaryngol 1997;39:133-8

11. Kaewboonchoo O, Morioka I, Miyashita K, et al. Hearing impairment among young Chinese in an urban area. Public Health 1998;112:143-6.

12. Mehra S, Eavey RD, Keamy DG. The epidemiology of hearing impairment in the United States: newborns, children, and adolescents. Otolaryngol Head Neck Surg 2009;140:461-72.

13. Rao RS, Subramanyam MA, Nair NS, et al. Hearing impairment and ear diseases among children of school entry age in rural South India. Int J Pediatr Otorhinolaryngol 2002;64:105-10.

14. Hixon B, Chan S, Adkins M, et al. Timing and impact of hearing healthcare in adult cochlear implant recipients: a rural-urban comparison. Otol Neurotol 2016;37:1320-4.

15. Ministry of Health and Welfare. Statistics of general health and welfare. Ministry of Health and Welfare. Taipei, Taiwan: Ministry of Health and Welfare, 2014.

16. Disabled Welfare Act. President Order Tai-Tung Yi-Tzu No 3028, 1980.

17. People with Disabilities Rights Protection Act. President Order HuaTsung-Yi-Tzu No 8600097810 1997, 1997.

18. Ministry of Health and Welfare. Taiwan health and welfare report. Ministry of Health and Welfare. Taipei, Taiwan: Ministry of Health and Welfare, 2014.

19. Teng S-W, Yen C-F, Liao H-F, et al. Evolution of system for disability assessment based on the international classification of functioning, disability, and health: a Taiwanese study. J Formos Med Assoc 2013;112:691-8.

20. Bagshaw RJ, Wall EH, Dowswell G, et al. Hearing impairment in otitis media with effusion: a cross-sectional study based in Pokhara, Nepal. Int J Pediatr Otorhinolaryngol 2011;75:1589-93.

21. Ministry of the Interior. Monthly bulletin of interior statistics: 1.11 population by year of age and median age. Taipei, Taiwan: Department of Statistics, Ministry of the Interior, 2010.

22. Ministry of the Interior. Monthly bulletin of interior statistics: 1.7 population for township and district and by urban area. Taipei, Taiwan: Department of Statistics, Ministry of the Interior, 2010.

23. Seely DR, Gloyd SS, Wright AD, et al. Hearing loss prevalence and risk factors among Sierra Leonean children. Arch Otolaryngol Head Neck Surg 1995;121:853-8.
24. Minja BM, Machemba A. Prevalence of otitis media, hearing impairment and cerumen impaction among school children in rural and urban Dar es Salaam, Tanzania. Int J Pediatr Otorhinolaryngol 1996;37:29-34.

25. Morioka I, Luo WZ, Miyashita K, et al. Hearing impairment among young Chinese in a rural area. Public Health 1996;110:293-7.

26. Kalpana R, Chamyal PC. Study of prevalence and aetiology of the hearing loss amongst school going children. Indian J Otolaryngol Head Neck Surg 1997;49:142-4.

27. Olusanya BO, Okolo AA, ljaduola GT. The hearing profile of Nigerian school children. Int J Pediatr Otorhinolaryngol 2000;55:173-9.

28. Flamme GA, Mudipalli VR, Reynolds SJ, et al. Prevalence of hearing impairment in a rural midwestern cohort: estimates from the Keokuk County Rural Health Study, 1994 to 1998. Ear Hear 2005;26:350-60.

29. Schmitz J, Pillion JP, LeClerq SC, et al. Prevalence of hearing loss and ear morbidity among adolescents and young adults in rural southern Nepal. Int J Audiol 2010;49:388-94.

30. Gondim LM, Balen SA, Zimmermann KJ, et al. Study of the prevalence of impaired hearing and its determinants in the city of Itajaí, Santa Catarina State, Brazil. Braz J Otorhinolaryngol 2012;78:27-34.

31. Jensen RG, Koch A, Homøe P. The risk of hearing loss in a population with a high prevalence of chronic suppurative otitis media. Int J Pediatr Otorhinolaryngol 2013;77:1530-5.

32. Feder KP, Michaud D, McNamee J, et al. Prevalence of hearing loss among a representative sample of Canadian children and adolescents, 3 to 19 years of age. Ear Hear 2017;38:7-20.

33. Durkin M. The epidemiology of developmental disabilities in lowincome countries. Ment Retard Dev Disabil Res Rev 2002;8:206-11.

34. Wang $\mathrm{Y}-\mathrm{Q}, \mathrm{C}-\mathrm{L} \mathrm{Y}, \mathrm{S}-\mathrm{W} \mathrm{X}$, et al. A report of $\mathrm{WHO}$ ear and hearing disorders survey in Guizhou Province. J Otol 2010;5:61-7.

35. Bastos I, Mallya J, Ingvarsson L, et al. Middle ear disease and hearing impairment in northern Tanzania. A prevalence study of schoolchildren in the Moshi and Monduli Districts. Int $J$ Pediatr Otorhinolaryngol 1995;32:1-12.

36. Elemraid MA, Brabin BJ, Fraser WD, et al. Characteristics of hearing impairment in Yemeni children with chronic suppurative otitis media: a case-control study. Int J Pediatr Otorhinolaryngol 2010;74:283-6.

37. Van Naarden K, Decouflé P, Caldwell K. Prevalence and characteristics of children with serious hearing impairment in metropolitan Atlanta, 1991-1993. Pediatrics 1999;103:570-5.

38. Fortnum HM, Summerfield AQ, Marshall DH, et al. Prevalence of permanent childhood hearing impairment in the United Kingdom and implications for universal neonatal hearing screening: questionnaire based ascertainment study. BMJ 2001;323:536-40.

39. Huang CM, Yang IY, Ma YC, et al. The effectiveness of the promotion of newborn hearing screening in Taiwan. Int $J$ Pediatr Otorhinolaryngol 2014;78:14-18.

40. Ministry of Health and Welfare. Health promotion administration annual report. Health Promotion Administration, Ministry of Health and Welfare. Taipei, Taiwan: Ministry of Health and Welfare, 2014. 